\title{
Association of Vitamin D and Parathyroid Hormone with Insulin Sensitivity, Beta Cell Function and Gestational Diabetes in Pregnancy: A Cross-Sectional, Observational Study
}

Amit Nachankar · Narendra Kotwal · Vimal Upreti · Vishesh Verma •

K. V. S. Hari Kumar (D)

Received: August 11, 2018 / Published online: September 11, 2018

(C) The Author(s) 2018

\section{ABSTRACT}

Introduction: Vitamin D (25OHD) and parathyroid hormone (PTH) are associated with dysglycemia, and we investigated them in gestational diabetes mellitus (GDM).

Methods: In this cross-sectional, observational study, we included 75 pregnant women between 24 and 28 weeks of gestation. A fasting venous sample was collected for plasma glucose (FPG), insulin, PTH and 25OHD. Glucose and insulin samples were collected hourly after $75 \mathrm{~g}$ glucose load for $2 \mathrm{~h}$. Insulin sensitivity was estimated by the Matsuda index (MI) and beta cell function by the insulin secretion sensitivity index (ISSI-2). The subjects were stratified into three groups and tertiles according to the 25OHD and PTH, respectively. Appropriate statistical tests were used to compare the MI, ISSI-2 and GDM among the groups.

Results: GDM was seen in $14 / 75$, and of these patients, 2 were $25 \mathrm{OHD}$ deficient, 7 insufficient and 5 had sufficient 25OHD. MI and ISSI-2, though not correlated with the 25OHD,

Enhanced Digital Features To view enhanced digital features for this article go to https://doi.org/10.6084/ m9.figshare.7049165.

A. Nachankar · N. Kotwal · V. Upreti · V. Verma .

K. V. S. Hari Kumar ( $\square)$

Department of Endocrinology, Army Hospital

(R\&R), Delhi Cantt, New Delhi, India

e-mail: hariendo@rediffmail.com decreased from the lower to higher PTH tertile $(P<0.001)$. FPG, AUCgluc (area under the curve glucose) and prevalence of GDM increased from the lower to higher PTH tertile $(P<0.001)$.

Conclusion: Increased PTH was associated with decreased insulin sensitivity, beta cell function and GDM in pregnancy, irrespective of the underlying 25OHD level.

Keywords: 25-Hydroxy vitamin D; Gestational diabetes; Insulin resistance; Parathyroid hormone

\section{INTRODUCTION}

Pregnancy is a diabetogenic state due to changes in the insulin sensitivity and beta cell function in previously healthy women. The Hyperglycemia and Adverse Pregnancy Outcome (HAPO) Study showed a continuous association between the maternal glucose level and increased birth weight, contributed by fetal hyperinsulinemia [1]. Vitamin D deficiency (VDD) has been described as a risk factor for type 2 diabetes (T2D) and gestational diabetes mellitus (GDM) [2]. Vitamin D has an effect on beta cell function, insulin sensitivity and inflammatory markers both directly and indirectly [3]. The pathways include stimulating the expression of the insulin receptors, activating the PPAR- $\delta$ (peroxisome proliferator activator 
receptor) pathway, improving oxidative phosphorylation in the muscle, reducing proinflammatory cytokines and increasing the intracellular calcium level [3]. Vitamin D plays an important role in feto-maternal medicine, and the vitamin $\mathrm{D}$ requirement increases during pregnancy [4]. A limited number of studies have investigated the association between GDM and VDD in the context of insulin resistance and beta cell function $[5,6]$.

Vitamin D and parathyroid hormone (PTH) share an inverse relationship physiologically. PTH has an independent effect on dysglycemia and is a modifiable risk factor for the development of GDM in patients with VDD [7]. PTH facilitates glucose-induced insulin release from beta cells by increasing the cytosolic calcium and stimulating the production of cAMP (cyclic Adenosine Mono Phosphate) [8]. However, PTH also increases insulin resistance by downregulating the insulin receptors peripherally and has a direct effect on beta cells [9]. The net effect of PTH on glycemic metabolism is controversial and has not been defined clearly. The majority of the studies pertaining to VDD and GDM have not factored in the independent role of PTH on the glycemic level $[10,11]$. Therefore, we conducted this study to evaluate the association of vitamin D and PTH levels on insulin sensitivity and beta cell function in patients with GDM.

\section{METHODS}

\section{Study Population}

This cross-sectional, observational study was conducted at a tertiary level Armed Forces hospital between December 2016 and June 2017. Pregnant women (24-28 weeks of pregnancy) who reported for GDM screening were included in the study. All the study participants reside in India and their genetic background is the South Asian race. We excluded patients with twin pregnancy, pre-existing DM and past history of GDM. We excluded patients with any major medical ailment, glucocorticoid use of any dose in the preceding 3 months and past history of hyperparathyroidism. The local ethics committee approved the trial protocol, and informed consent was obtained from all patients for being included in the study. All procedures followed in the study were in accordance with the ethical standards of the responsible committee on human experimentation (institutional and national) and with the Helsinki Declaration of 1964, as revised in 2013.

\section{Study Measures}

A detailed history regarding the medical, obstetric and family profile of diabetes was obtained from all the participants. A general physical examination was carried out with specific reference to the anthropometric measures and signs of insulin resistance. Body mass index (BMI) is defined as weight in kilograms divided by height in meters squared. A fasting venous blood sample was collected from each participant after an overnight fast of $10 \mathrm{~h}$. This sample was analyzed for glucose, 25-hydroxyvitamin D (25OHD), PTH, insulin and glycosylated hemoglobin (HbA1c). Thereafter, patients were given $75 \mathrm{~g}$ glucose solution orally, and venous samples were collected after 1 and $2 \mathrm{~h}$ for estimation of glucose and insulin. Glucose was estimated by the glucose oxidase method within $1 \mathrm{~h}$ of the sample collection and HbA1c by the cation exchange high-performance liquid chromatography method using the D10 hemoglobin testing system manufactured by Bio-Rad Laboratories. The levels of insulin, 25OHD and PTH were estimated with the IRMA kit (Beckman Coulter) using the Stratec SR300 automated radioimmunoassay system (STRATEC Biomedical Systems AG, Birkenfeld, Germany). The inter- and intraassay coefficient of variation for all the tests is $<8 \%$ in our laboratory.

\section{Study Definitions}

GDM was diagnosed according to the American Diabetes Association (ADA) criteria when any one of the following criteria was met after a $75 \mathrm{~g}$ OGTT (fasting $>92 \mathrm{mg} / \mathrm{dl}, 1 \mathrm{~h}>180$ and $2 \mathrm{~h}>153 \mathrm{mg} / \mathrm{dl}$ ) [12]. Insulin sensitivity was calculated using the Matsuda index [13]. We calculated the area under the curve (AUC) for 
insulin (pmol/l) and glucose ( $\mathrm{mmol} / \mathrm{l})$ using the OGTT (oral glucose tolerance test) derived values and the trapezoidal rule. Beta cell function was estimated using the Insulin Secretion-Sensitivity Index-2 (ISSI-2), which is a validated measure derived from the OGTT [14]. It is a product of insulin secretion measured by the ratio of the AUC insulin curve to AUC glucose and insulin sensitivity. We stratified the patients, according to the levels of vitamin D and $\mathrm{PTH}$. The patients were divided into three groups (D1, D2 and D3) based on 25OHD according to the Endocrine Society guidelines into deficiency $(\leq 20 \mathrm{ng} / \mathrm{ml})$, insufficiency (21-30) and sufficiency (25OHD $>30 \mathrm{ng} / \mathrm{ml}$ ), respectively [15]. The patients were divided into three groups based on the PTH level as P1 $(\mathrm{PTH} \leq 15 \mathrm{pg} / \mathrm{ml}), \quad \mathrm{P} 2$ (PTH 15.1-30) and P3 $(\mathrm{PTH}>30 \mathrm{pg} / \mathrm{ml})$.

\section{Statistics}

Continuous variables are presented as mean (SD), and categorical variables are presented as absolute numbers and percentage. Data were checked for normality before statistical analysis. One-way analysis of variance (ANOVA) was used to evaluate the significance of the differences among the three PTH and 25OHD groups. Multivariate linear regression analyses were done to evaluate independent associations of vitamin D and PTH groups with insulin sensitivity and beta cell function. $P<0.05$ was taken as significant in all the tests. The statistical analysis was performed using the SPSS program for Windows, version 17.0 (SPSS, Chicago, IL, USA).

\section{RESULTS}

The study participants comprised 75 pregnant women with a mean age of 27.5 (2.9) years, mean gestational age 26.7 (0.7) weeks, body weight 57.8 (6.5) $\mathrm{kg}$ and mean BMI 23.2 (1.9) $\mathrm{kg} / \mathrm{m}^{2}$. Fourteen of $75(18.7 \%)$ patients were diagnosed with GDM, and family history of DM was present in 24/75 (32\%) women. The mean 25OHD level was 25.7 (7.6) ng/ml, PTH
26.7 (15) pg/ml, Matsuda index 4.4 (1.7) and mean ISSI-2 244.9 (68.1) in the entire study population. Patient characteristics based on their 25OHD level are shown in Table 1. 25OHD was deficient in 19 (25\%), insufficient in $39(52 \%)$ and sufficient in 17 (23\%) participants. The prevalence of GDM in each 25OHD group was not significantly different $(P=0.0661)$, though the percentage of women with GDM increased with improving 25OHD level. Insulin sensitivity and beta cell function showed no difference according to the underlying 25OHD level. The FPG and HbA1c of women across all three groups of $25 \mathrm{OHD}$ were also similar.

The comparison of the patients based on the PTH groups is shown in Table 2. Twenty-three women were in the first group ( $\leq 15 \mathrm{pg} / \mathrm{ml}), 29$ in the second and 23 in the third group $(>30 \mathrm{pg} / \mathrm{ml})$. The patients in different PTH groups did not differ in age, BMI, gestational age or the season of blood collection, as shown in Table 2. GDM was more prevalent in the third group (higher PTH) compared with the others. Insulin sensitivity and beta cell function also decreased significantly from the first (low) to third (high) PTH group. The analysis of patients with and without GDM is shown in Table 3. Briefly, patients with GDM had higher weight gain and PTH levels and were insulin resistant with reduced beta cell function.

A simple univariate correlation analysis between the important clinical and biochemical parameters is shown in Table 4 . Correlation analyses revealed that $25 \mathrm{OHD}$ is inversely related to the PTH in the entire study population $(R=-0.5162 ; P<0.001)$. PTH correlated significantly with the insulin sensitivity $(R=-0.4889 ; P<0.001)$ and beta cell function $(R=-0.2985 ; \quad P=0.0093), \quad$ whereas 25OHD showed an insignificant correlation with the insulin sensitivity $(R=0.0934$; $P=0.4253)$ and beta cell function $(R=0.1001$; $P=0.3926$ ), as shown in Fig. 1 . The results of the multivariate analysis for the risk of GDM with the study parameters is shown in Table 5 . Increased BMI and VDD and elevated PTH raise the risk of GDM independent of other parameters. 
Table 1 Comparison of parameters according to the 25OHD level

\begin{tabular}{|c|c|c|c|c|}
\hline Features & D1 $(25 \mathrm{OHD} \leq 20)$ & D2 (25OHD 21-30) & D3 $(25$ OHD > 30) & $P$ value \\
\hline Number (\%) & $19(25.3 \%)$ & $39(52 \%)$ & $17(22.7 \%)$ & \\
\hline Age (years) & $27.2(3.3)^{*}$ & $27.5(3.1)$ & $27.6(2.5)$ & 0.9031 \\
\hline Family h/o DM $(n)$ & $5(26.3 \%)$ & $14(35.5 \%)$ & $5(29.4 \%)$ & 0.7382 \\
\hline Gestational age (weeks) & $26.8(0.96)$ & $26.7(0.96)$ & $26.9(1.1)$ & 0.6943 \\
\hline Height $(\mathrm{cm})$ & $156.2(4.6)$ & $156.9(5.8)$ & $156.9(5.5)$ & 0.8794 \\
\hline Weight $(\mathrm{kg})$ & $56.6(6.4)$ & $57.7(7.1)$ & $57.2(7.2)$ & 0.8695 \\
\hline $\operatorname{BMI}\left(\mathrm{kg} / \mathrm{m}^{2}\right)$ & $23.2(2.1)$ & $23.4(1.9)$ & $23.2(1.8)$ & 0.9286 \\
\hline Weight gain $(\mathrm{kg})$ & $5.3(0.67)$ & $5.5(0.86)$ & $5.4(0.75)$ & 0.8627 \\
\hline Summer/winter & $17 / 2$ & $29 / 10$ & $15 / 2$ & 0.2718 \\
\hline $\mathrm{Ca} /$ Vit D use & $2(10.5 \%)$ & $10(26 \%)$ & $6(35.3 \%)$ & 0.2089 \\
\hline $25 \mathrm{OHD}(\mathrm{ng} / \mathrm{ml})$ & $12.2(2.7)$ & $25(2.6)$ & $36.7(5.2)$ & $<0.001$ \\
\hline PTH (pg/ml) & $37.6(12.2)$ & $25.4(13.3)$ & $17.4(14.5)$ & $<0.001$ \\
\hline HbAlc (\%) & $5.2(0.73)$ & $5.2(0.78)$ & $5.3(0.94)$ & 0.9081 \\
\hline Matsuda index & $4.1(1.4)$ & $4.5(1.7)$ & $4.4(2.1)$ & 0.7122 \\
\hline ISSI-2 & $244.7(77.4)$ & $242.9(60.9)$ & $250.1(76.5)$ & 0.9383 \\
\hline $\mathrm{FPG}(\mathrm{mmol} / \mathrm{l})$ & $4.6(0.6)$ & $4.7(0.7)$ & $4.9(0.9)$ & 0.8843 \\
\hline Glucose $1 \mathrm{~h}$ post OGTT & $9(1.1)$ & $8.9(1.2)$ & $9(1.5)$ & 0.4432 \\
\hline Glucose $2 \mathrm{~h}$ post OGTT & $7.6(1.1)$ & $7.3(1.3)$ & $7.2(1.6)$ & 0.6394 \\
\hline AUCgluc $\left(\mathrm{mmol} / \mathrm{l}^{*} 1 \mathrm{~h}\right)$ & $15.2(1.9)$ & $14.9(2.1)$ & $15.1(2.7)$ & 0.9375 \\
\hline GDM cases (\%) & $2(10.5 \%)$ & $7(17.9 \%)$ & $5(29.4 \%)$ & 0.0661 \\
\hline
\end{tabular}

All significant $P$ values are highlighted in bold

${ }^{*}$ Mean (SD)

\section{DISCUSSION}

Our study showed that insulin sensitivity and beta cell function were related to the PTH level independent of the underlying 25OHD. The patients in the highest PTH group had a higher prevalence of GDM compared with the other two groups. Although previous studies have suggested a role of PTH in glucose homeostasis in the general population, few studies have addressed this issue in pregnancy. Whitelaw et al. showed that PTH was weakly associated with FPG but not with 2-h glucose or GDM [16]. In contrast, in a cross-sectional assessment in the late second trimester, Zuhur et al. found that PTH was higher in women with GDM than in their peers on unadjusted comparison [17]. Our study demonstrated a negative correlation of PTH with the Matsuda index and ISSI-2, as shown in Fig. 1. The inverse relation between the PTH level and ISSI-2 suggests beta cell dysfunction as a potential pathophysiologic mechanism through which increased PTH may be linked to dysglycemia in pregnancy. PTH may be an unrecognized biologic factor contributing to the insulin resistance in patients with VDD. PTH is a key indicator of $25 \mathrm{OHD}$ status, and interindividual variations exist in 
Table 2 Comparison of parameters according to the PTH value

\begin{tabular}{|c|c|c|c|c|}
\hline Feature & P1 $($ PTH $\leq 15)$ & P2 (PTH 15.1-30) & P3 $($ PTH > 30) & $P$ value \\
\hline Number & $23(31 \%)$ & $29(38 \%)$ & $23(31 \%)$ & \\
\hline Age (years) & $27.7(2.8)^{*}$ & $27.2(2.8)$ & $27.6(3.4)$ & 0.7872 \\
\hline Family h/o DM (n) & $5(21.7 \%)$ & $8(27.6 \%)$ & $11(47.8 \%)$ & 0.1342 \\
\hline Gestation at OGTT (weeks) & $26.7(1)$ & $26.8(1.01)$ & $26.7(0.96)$ & 0.9704 \\
\hline BMI $\left(\mathrm{kg} / \mathrm{m}^{2}\right)$ & $23.4(1.6)$ & $22.7(2)$ & $23.8(1.9)$ & 0.1262 \\
\hline Weight gain $(\mathrm{kg})$ & $5.3(0.7)$ & $5.3(0.66)$ & $5.7(0.95)$ & 0.1414 \\
\hline Summer/winter $(n)$ & $4 / 19$ & $7 / 22$ & $3 / 20$ & 0.5827 \\
\hline $\mathrm{Ca} /$ Vit D use $(n)$ & $8(34.8 \%)$ & $6(20.7 \%)$ & $4(17.4 \%)$ & 0.3345 \\
\hline $25 \mathrm{OHD}(\mathrm{ng} / \mathrm{ml})$ & $32.6(7.4)$ & $23.5(3.9)$ & $21.6(6.7)$ & $<0.0001$ \\
\hline PTH $(\mathrm{pg} / \mathrm{ml})$ & $11.6(1.8)$ & $23.3(4)$ & $46.2(8.9)$ & $<0.0001$ \\
\hline HbAlc (\%) & $5(0.78)$ & $4.9(0.54)$ & $5.7(0.9)$ & 0.0026 \\
\hline Matsuda index & $5.3(1.4)$ & $4.4(1.2)$ & $2.9(1.4)$ & $<0.0001$ \\
\hline ISSI-2 & $271.7(59.7)$ & $248.5(48.3)$ & $213.7(85.3)$ & 0.0124 \\
\hline FPG (mmol/l) & $4.3(0.4)$ & $4.8(0.7)$ & $5.3(0.3)$ & $<0.0001$ \\
\hline Glucose $1 \mathrm{~h}$ post OGTT & $8.4(1)$ & $8.6(0.9)$ & $9.6(1.4)$ & 0.0017 \\
\hline Glucose $2 \mathrm{~h}$ post OGTT & $6.7(1.1)$ & $7.2(1)$ & $8.1(1.5)$ & 0.0016 \\
\hline AUCgluc $\left(\mathrm{mmol} / \mathrm{l}^{*} 1 \mathrm{~h}\right)$ & $14.1(1.8)$ & $14.7(1.4)$ & $16.4(2.8)$ & 0.0008 \\
\hline GDM cases $(n)$ & $3(13 \%)$ & $2(6.9 \%)$ & $9(39.1 \%)$ & 0.0088 \\
\hline
\end{tabular}

All significant $P$ values are highlighted in bold

${ }^{*}$ Mean (SD)

the level of $25 \mathrm{OHD}$ that provides maximal PTH suppression [18].

Our data showed the presence of VDD in a majority of the study participants. Previous studies have shown that VDD is a common problem in Indian women [19]. The literature is conflicting about the role of 25OHD in GDM. Our study showed an equal prevalence of VDD in patients with and without GDM. Similar to our study, Farrant et al. found that hypovitaminosis D at 30-week gestation is not associated with an increased risk of GDM [11]. In a crosssectional study involving more than 1400 patients from the developed world, Whitelaw et al. demonstrated that 25OHD was not associated with theinsulin concentration or GDM [16]. Another study from India showed a strong association between the levels of 25OHD and GDM, though the 25OHD replacement did not reverse the gestational dysglycemia [20]. Zuhur et al. showed that GDM is associated with only severe VDD and not with mild or moderate deficiency [17]. The conflicting links between vitamin D and GDM could be explained by the differences in the study population, sun exposure, food fortification, VDD definition and measurement of 25OHD [21].

The best available index of insulin sensitivity during pregnancy is the NEFA (non-esterified fatty acid) index based on the insulin level and BMI [22]. This is cumbersome and is not widely available for performing in clinical practice. The Matsuda index is considered very useful for assessment of insulin secretion as it shows a 
Table 3 Comparison between the patients with and without GDM

\begin{tabular}{llll}
\hline Feature & GDM absent & GDM present & P value \\
\hline Number & $61(81 \%)$ & $14(19 \%)$ & \\
Age (years) & $27.4(2.9)^{*}$ & $27.7(3.3)$ & 0.7350 \\
Family h/o DM $(n)$ & $16(26.2 \%)$ & $8(57.1 \%)$ & 0.0528 \\
Gestation at OGTT (weeks) & $26.8(0.9)$ & $26.8(1.1)$ & 0.9146 \\
BMI $\left(\mathrm{kg} / \mathrm{m}^{2}\right)$ & $23.1(1.9)$ & $24.1(1.9)$ & 0.0886 \\
Weight gain $(\mathrm{kg})$ & $5.2(0.6)$ & $6.4(0.8)$ & $<\mathbf{0 . 0 0 0 1}$ \\
Summer/winter $(n)$ & $51 / 10$ & $10 / 4$ & 0.2818 \\
Ca/Vit D use $(n, \%)$ & $13(21.3 \%)$ & $5(35.7 \%)$ & 0.3028 \\
PTH (pg/ml) & $24.4(13.4)$ & $36.8(17.9)$ & $\mathbf{0 . 0 0 4 3}$ \\
25OHD (ng/ml) & $25.3(7.7)$ & $27.3(6.8)$ & 0.3897 \\
HbAlc $(\%)$ & $4.9(0.3)$ & $6.7(0.5)$ & $<\mathbf{0 . 0 0 0 1}$ \\
Matsuda index & $5(1.1)$ & $1.6(0.44)$ & $<\mathbf{0 . 0 0 0 1}$ \\
ISSI-2 & $267.5(53.6)$ & $147(21.3)$ & $<\mathbf{0 . 0 0 0 1}$ \\
FPG (mmol/l) & $4.5(0.3)$ & $6.2(0.8)$ & $<\mathbf{0 . 0 0 0 1}$ \\
Glucose 1 h post OGTT & $8.5(0.6)$ & $11.1(0.8)$ & $<\mathbf{0 . 0 0 0 1}$ \\
Glucose 2 h post OGTT & $6.9(0.7)$ & $9.4(0.5)$ & $<\mathbf{0 . 0 0 0 1}$ \\
AUCgluc (mmol//*1 h) & $14.5(1.3)$ & $16.8(2.2)$ & $<\mathbf{0 . 0 0 0 1}$ \\
\hline All sgnf & &
\end{tabular}

All significant $P$ values are highlighted in bold

${ }^{*}$ Mean $(\mathrm{SD})$

stronger correlation with clamp-measured insulin sensitivity than other surrogate measures in pregnancy. The QUICKI and HOMA indices, which are based on a single blood sample, can also provide an easy but accurate measure of insulin sensitivity in pregnant women [23]. We used the Matsuda index for assessment of insulin sensitivity and ISSI-2 for the assessment of beta cell function. Lacroix et al. used HOMA-IR, beta cell function (HOMAB), the Matsuda index and beta cell compensation (ISSI-2) [6]. Similar to our study, Kramer et al. used the Matsuda index and ISSI-2 in their study involving pregnant women [24].

Our study has many strengths, as explained below. First, we assessed the insulin sensitivity using the Matsuda index, which correlated strongly with insulin clamp-measured insulin sensitivity compared with other surrogate measures in pregnancy. Second, the beta cell function was assessed by ISSI-2, which is a validated OGTT-derived measure of beta cell function and has been directly validated against the disposition index from intravenous GTT. Third, we estimated the 25OHD and PTH simultaneously in relation to glycemia, unlike many previous studies. The limitations of our study include the small sample size, cross-sectional design and lack of estimation of active vitamin $\mathrm{D}$ and binding protein, which could provide more comprehensive information about this metabolic pathway. Pregnancy affects the assessment of total vitamin $D$, and few authors have suggested using the free form of vitamin D for accurate diagnosis of VDD [25]. The PTH assay methods using the immunometric technique measure the oxidized PTH, which is a biologically inactive molecule, 
Table 4 Simple univariate correlation matrix

\begin{tabular}{lllllll}
\hline Parameter & Age & BMI & 25OHD & PTH & FPG & HbA1c \\
\hline Age & - & $R=0.0865$ & $R=0.1149$ & $R=-0.0604$ & $R=-0.1055$ & $R=-0.0834$ \\
& & $P=0.4598$ & $P=0.3262$ & $P=0.6065$ & $P=0.3678$ & $P=0.4767$ \\
BMI & $R=0.0865$ & - & $R=0.1455$ & $R=0.05916$ & $R=0.2096$ & $R=0.2952$ \\
& $P=0.4598$ & & $P=0.2130$ & $P=0.6141$ & $P=0.0711$ & $\boldsymbol{P}=\mathbf{0 . 0 1 0 1}$ \\
25OHD & $R=0.1149$ & $R=0.1455$ & - & $R=-0.5162$ & $R=-0.0307$ & $R=-0.0145$ \\
& $P=0.3262$ & $P=0.2130$ & & $\boldsymbol{P}=<\mathbf{0 . 0 0 0 1}$ & $P=0.7937$ & $P=0.9012$ \\
PTH & $R=-0.0604$ & $R=0.05916$ & $R=-0.5162$ & - & $R=0.4260$ & $R=0.3694$ \\
& $P=0.6065$ & $P=0.6141$ & $\boldsymbol{P}=<\mathbf{0 . 0 0 0 1}$ & & $\boldsymbol{P}=\mathbf{0 . 0 0 0 1}$ & $\boldsymbol{P}=\mathbf{0 . 0 0 1 1}$ \\
FPG & $R=-0.1055$ & $R=0.2096$ & $R=-0.0307$ & $R=0.4260$ & - & $R=0.8686$ \\
& $P=0.3678$ & $P=0.0711$ & $P=0.7937$ & $\boldsymbol{P}=\mathbf{0 . 0 0 0 1}$ & & $\boldsymbol{P}=<\mathbf{0 . 0 0 0 1}$ \\
HbA1c & $R=-0.0834$ & $R=0.2952$ & $R=-0.0145$ & $R=0.3694$ & $R=0.8686$ & - \\
& $P=0.4767$ & $\boldsymbol{P}=\mathbf{0 . 0 1 0 1}$ & $P=0.9012$ & $\boldsymbol{P}=\mathbf{0 . 0 0 1 1}$ & $\boldsymbol{P}=<\mathbf{0 . 0 0 0 1}$ & \\
\hline
\end{tabular}

All significant $P$ values are highlighted in bold

A

Correlation of Vit D and Matsuda index

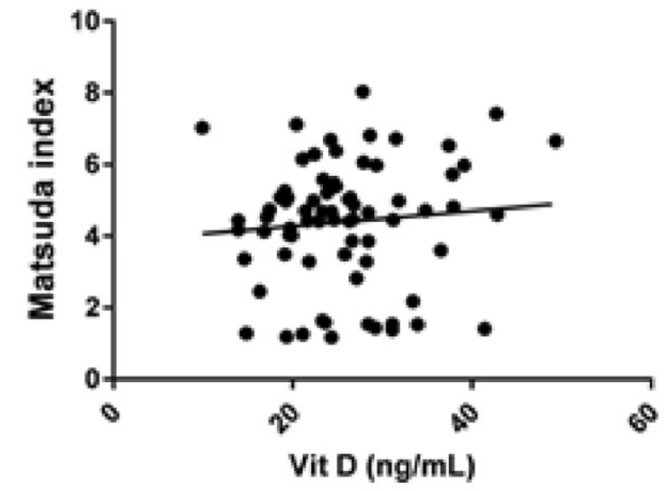

C Correlation of PTH and Matsuda index

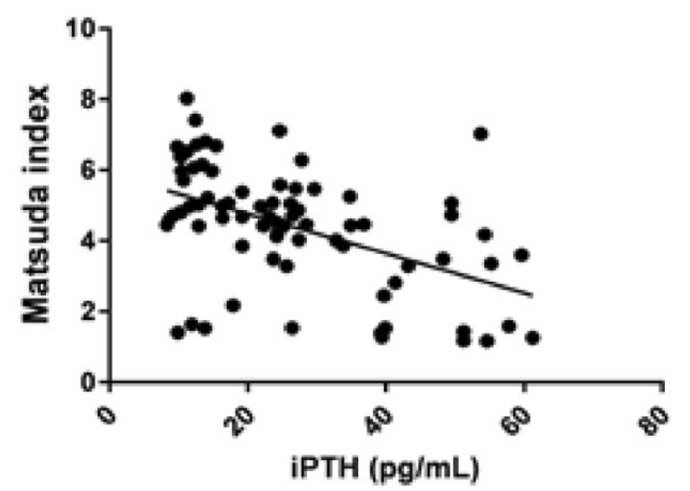

B

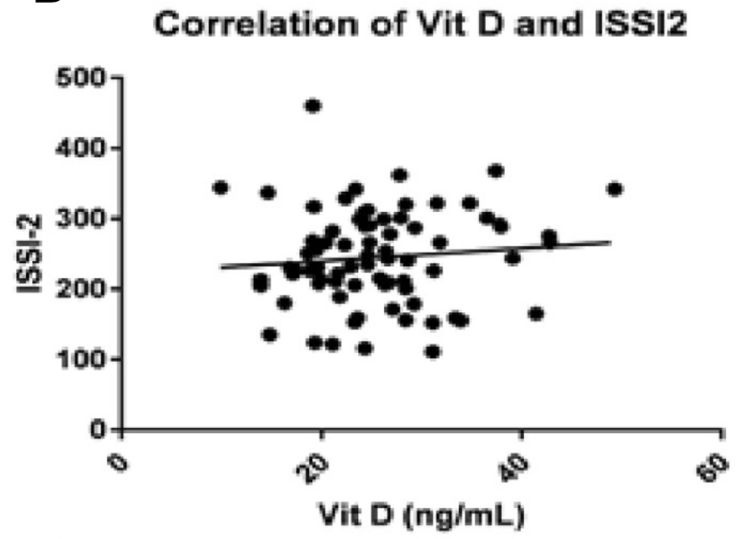

D Correlation of PTH and ISSI-2

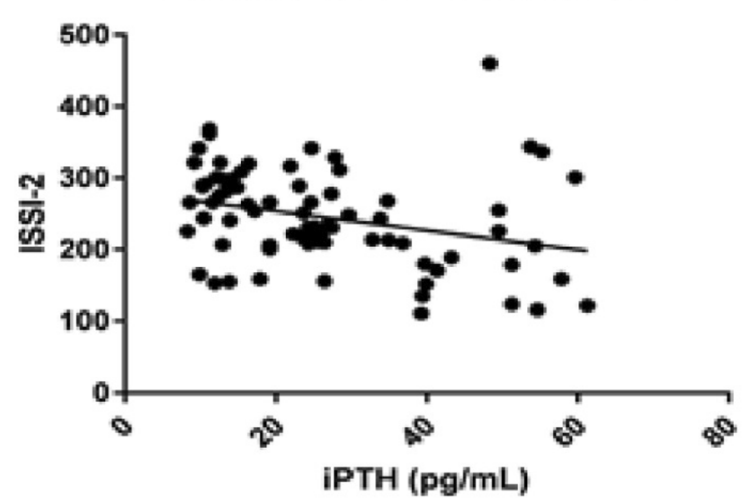

Fig. 1 Correlation analyses among vitamin D, PTH with the Matsuda index and ISSI-2 
Table 5 Logistic multivariate regression analysis for the risk of developing GDM

\begin{tabular}{lcllll}
\hline Parameter & Coefficient & Standard error & Odds ratio & 95\% CI & $\boldsymbol{P}$ value \\
\hline Age & -0.053942 & 0.13755 & 0.9475 & $0.7236-1.2407$ & 0.6949 \\
BMI & 0.51948 & 0.23162 & 1.6812 & $1.0677-2.6471$ & $\mathbf{0 . 0 2 4 9}$ \\
Family h/o DM & 0.88737 & 0.76234 & 2.4287 & $0.5451-10.8217$ & 0.2444 \\
Gestational age & -0.092310 & 0.36886 & 0.9118 & $0.4425-1.8788$ & 0.8024 \\
25OHD & 0.13526 & 0.059754 & 1.1448 & $1.0183-1.2871$ & $\mathbf{0 . 0 2 3 6}$ \\
PTH & 0.090982 & 0.033457 & 1.0952 & $1.0257-1.1695$ & $\mathbf{0 . 0 0 6 5}$ \\
\hline
\end{tabular}

All significant $P$ values are highlighted in bold

thereby falsely elevating the PTH level [26, 27]. The measurement of total vitamin $\mathrm{D}$ instead of free vitamin D and the estimation of PTH by RIA assay are other methodologic limitations of our study.

\section{CONCLUSION}

To conclude, our study demonstrates that increased PTH was associated with decreased insulin sensitivity, beta cell dysfunction and dysglycemia in pregnancy. In contrast, the vitamin $\mathrm{D}$ level in pregnancy is not associated with GDM, insulin sensitivity and beta cell function. The PTH level may emerge as an underlying independent risk factor relevant to the interpretation of the links between 25OHD and GDM. Further prospective studies with large sample sizes are required to validate the findings observed in our study.

\section{ACKNOWLEDGEMENTS}

We thank the participants of the study.

Funding. No funding or sponsorship was received for this study or publication of this article.

Authorship. All named authors meet the International Committee of Medical Journal Editors (ICMJE) criteria for authorship for this manuscript, take responsibility for the integrity of the work as a whole and have given final approval to the version to be published.

Authorship Contributions. Amit Nachankar and Narendra Kotwal designed the study. K.V.S. Hari Kumar and Vimal Upreti analyzed the data and did statistical analyses. Vishesh Verma created the figures and K.V.S. Hari Kumar wrote the initial report. All the authors read and revised the report and approved the final submitted version. K.V.S. Hari Kumar assumes responsibility for the completeness and accuracy of the data and analyses.

Disclosures. All the authors (Amit Nachankar, Narendra Kotwal, Vimal Upreti, Vishesh Verma and K.V.S. Hari Kumar) have nothing to disclose.

Compliance with Ethics Guidelines. This article is compliant with all associated ethical guidelines, and permission was obtained from the institutional ethics committee for the study. All procedures followed were in accordance with the ethical standards of the responsible committee on human experimentation (institutional and national) and with the Helsinki Declaration of 1964, as revised in 2013. Informed consent was obtained from all patients for being included in the study.

Data Availability. The data sets generated during and/or analyzed during the current study are not publicly available because of the data pertaining to the military service personnel but are available from the corresponding author on reasonable request. 
Open Access. This article is distributed under the terms of the Creative Commons Attribution-NonCommercial 4.0 International License (http://creativecommons.org/licenses/ by-nc/4.0/), which permits any noncommercial use, distribution, and reproduction in any medium, provided you give appropriate credit to the original author(s) and the source, provide a link to the Creative Commons license, and indicate if changes were made.

\section{REFERENCES}

1. Hyperglycemia and Adverse Pregnancy Outcome (HAPO) Study Cooperative Research Group. Hyperglycemia and adverse pregnancy outcomes. N Engl J Med. 2008;358:1991-2002.

2. Song Y, Wang L, Pittas AG, et al. Blood 25-hydroxy vitamin $\mathrm{D}$ levels and incident type 2 diabetes: a meta-analysis of prospective studies. Diabetes Care. 2013;36:1422-8.

3. Stivelman E, Retnakaran R. Role of vitamin D in the pathophysiology and treatment of type 2 diabetes. Curr Diabetes Rev. 2012;8:42-7.

4. von Websky K, Hasan AA, Reichetzeder C, Tsuprykov $\mathrm{O}$, Hocher B. Impact of vitamin $\mathrm{D}$ on pregnancy-related disorders and on offspring outcome. J Steroid Biochem Mol Biol. 2018;180:51-64.

5. El Lithy A, Abdella RM, El-Faissal YM, Sayed AM, Samie RM. The relationship between low maternal serum vitamin D levels and glycemic control in gestational diabetes assessed by HbA1c levels: an observational cross-sectional study. BMC Pregnancy Childbirth. 2014;14:362.

6. Lacroix M, Battista MC, Doyon M, et al. Lower vitamin $\mathrm{D}$ levels at first trimester are associated with higher risk of developing gestational diabetes mellitus. Acta Diabetol. 2014;51:609-16.

7. Kramer CK, Swaminathan B, Hanley AJ, et al. Vitamin D and Parathyroid hormone status in pregnancy: effect on insulin sensitivity, beta cell function, and gestational diabetes mellitus. J Clin Endocrinol Metab. 2014;99:4506-13.

8. Chiu KC, Chuang LM, Lee NP, et al. Insulin sensitivity is inversely correlated with plasma intact parathyroid hormone level. Metabolism. 2000;49:1501-5.

9. Murray TM, et al. Parathyroid hormone secretion and action: Evidence for discrete receptors for the carboxyl-terminal region and related biological actions of carboxyl terminal ligands. Endocr Rev. $2005 ; 26: 78-113$.

10. Clifton-Bligh RJ, McElduff P, McElduff A. Maternal vitamin D deficiency, ethnicity and gestational diabetes. Diabet Med. 2008;25:678-84.

11. Farrant HJ, Krishnaveni GV, Hill JC, et al. Vitamin $\mathrm{D}$ insufficiency is common in Indian mothers but is not associated with gestational diabetes or variation in newborn size. Eur J Clin Nutr. 2009;63:646-52.

12. American Diabetes Association. 2. Classification and diagnosis of diabetes: standards of medical care in diabetes-2018. Diabetes Care. 2018;41:S13-27.

13. Matsuda M, DeFronzo RA. Insulin sensitivity indices obtained from oral glucose tolerance testing: comparison with the euglycemic insulin clamp. Diabetes Care. 1999;22:1462-70.

14. Saisho Y, Miyakoshi K, Tanaka M, et al. Beta cell dysfunction and its clinical significance in gestational diabetes. Endocr J. 2010;57:973-80.

15. Holick MF, Binkley NC, Bischoff-Ferrari HA, et al. Evaluation, treatment, and prevention of vitamin D deficiency: an Endocrine Society clinical practice guideline. J Clin Endocrinol Metab. 2011;96:1911-30.

16. Whitelaw DC, Scally AJ, Tuffnell DJ, et al. Associations of circulating calcium and 25-hydroxyvitamin D with glucose metabolism in pregnancy: a crosssectional study in European and South Asian women. J Clin Endocrinol Metab. 2014;99:938-46.

17. Zuhur SS, Erol RS, Kuzu I, et al. The relationship between low maternal serum 25-hydroxyvitamin D levels and gestational diabetes mellitus according to the severity of 25-hydroxyvitamin D deficiency. Clinics (Sao Paulo). 2013;68:658-64.

18. Reis JP, von Muhlen D, Kritz-Silverstein D, et al. Vitamin D, parathyroid hormone levels, and the prevalence of metabolic syndrome in communitydwelling older adults. Diabetes Care. 2007;30:1549-55.

19. Kumar KH, Kumar S, Dhillon AS, Mansingh S, Sood S. High prevalence of Vitamin D deficiency during pregnancy: a social health problem in India. J Soc Health Diabetes. 2016;4:36-40.

20. Muthukrishnan J, Dhruv G. Vitamin D status and gestational diabetes mellitus. Indian $\mathrm{J}$ Endocr Metab. 2015;19:616-9.

21. Tsuprykov O, Buse C, Skoblo R, Haq A, Hocher B. Reference intervals for measured and calculated free 25-hydroxyvitamin D in normal pregnancy. J Steroid Biochem Mol Biol. 2018;181:80-7. 
22. Wagner R, Fritsche L, Heni M, et al. A novel insulin sensitivity index particularly suitable to measure insulin sensitivity during gestation. Acta Diabetol. 2016;53:1037-44.

23. Kirwan JP, Huston-Presley L, Kalhan SC, Catalano PM. Clinically useful estimates of insulin sensitivity during pregnancy: validation studies in women with normal glucose tolerance and gestational diabetes mellitus. Diabetes Care. 2001;24:1602-7.

24. Kramer CK, Swaminathan B, Hanley AJ, et al. Prospective associations of vitamin D status with $\beta$ cell function, insulin sensitivity, and glycemia: the impact of parathyroid hormone status. Diabetes. 2014;63:3868-79.
25. Tsuprykov O, Chen X, Hocher CF, Skoblo R, Yin L, Hocher B. Why should we measure free $25(\mathrm{OH})$ vitamin D? J Steroid Biochem Mol Biol. 2018;180:87-104.

26. Hocher B, Zeng S. Clear the fog around parathyroid hormone assays: What do iPTH assays really measure? Clin J Am Soc Nephrol. 2018;13(4):524-6.

27. Hocher B, Pasch A. Hope for CKD-MBD Patients: new diagnostic approaches for better treatment of CKD-MBD. Kidney Dis (Basel). 2017;3(1):8-14. 